\title{
AMZOL: MULHERES DA PERIFERIA DE SÃO PAULO EM BUSCA DE PROTAGONISMO
}

\author{
Luiza E. Tomita*
}

\section{RESUMO}

O protagonismo tem sido a grande meta a ser alcançada pelas mulheres dentro da Igreja Católica, tendo em vista a recusa aos ministérios ordenados e aos cargos de decisão por sua hierarquia. O cristianismo patriarcal que dominou a Igreja cristã na ortodoxia clássica apresenta uma religião dirigida aos homens, pois mostrou, na perspectiva popular, a mulher como portadora do pecado. Embora tenha permitido que a mulher recebesse o Batismo, a teologia clássica ressaltava sua "maior propensão para o pecado" (Rosemary RUETHER, 1993, p. 84), baseada no mito de origem de Adão e Eva que "naturalizou" a culpa das mulheres. Desta forma, a culpabilização foi sempre uma forma de manter as mulheres submissas e a não se rebelarem contra o seu papel de submissão no lar e na Igreja. Este texto visa enfocar a luta por protagonismo de mulheres das periferias, que começaram como membros de Comunidades Eclesiais de Base na zona leste de São Paulo e acabaram criando uma associação popular - AMZOL - para protagonizar lutas sociais e políticas na região a partir da década de 1960. Elas se transformaram em promotoras legais populares, criaram o Centro Maria Miguel (um setor da AMZOL) de combate à violência doméstica, tendo a parceria da Procuradoria Geral do Estado de São Paulo. e acabaram por conquistar importantes políticas públicas. Para bem iluminar sua trajetória enquanto mulheres de periferia, este texto inicia com uma breve revisão histórica de como a revolução industrial e o advento do capitalismo colaboraram para o recrudescimento do processo de subalternidade e submissão das mulheres quando elas tentaram entrar para o mudo do trabalho e, em seguida, aborda

* Luiza Etsuko Tomita, doutora em Teologia Sistemática pela Universidade Metodista de São Paulo e mestra em Estudos Bíblicos pela Pontifícia Faculdade de Teologia N.S. da Assunção , é ex-presidente de EATWOT (Ecumenical Association of Third World Theologians) 2011-2016, é integrante do Conselho Permanente Internacional do FMTL (Fórum Mundial de Teologia e Libertação) desde 2008, foi professora de teologia e estudos bíblicos em faculdades de São Paulo até o ano de 2010. 
como o Vaticano empreendeu uma cruzada para combater a ameaça do ateísmo militante e do comunismo através da Ação Católica, um empreendimento dirigido ao laicato, ainda de cunho patriarcal e bastante elitista. Portanto, foi a militância feminista que empoderou as mulheres das periferias e permitiu importantes conquistas sociais e políticas nas periferias dos grandes centros urbanos.

Palavras chave: mulheres de periferia, Igreja, protagonismo, políticas públicas, promotoras legais populares.

\section{AMZOL: WOMEN FROM THE PERIPHERY OF SÃO PAULO IN SEARCH OF PROTAGONISM}

\section{ABSTRACT}

Protagonism has been the great goal to be achieved by women within the Catholic Church, in view of the rejection of ordained ministries and decision-making positions by their hierarchy. The patriarchal Christianity that ruled the Christian Church in classical orthodoxy presents a religion focused on men, as it is showed by the popular perspective that puts women as the bearer of the sin. While allowing women to receive the Baptism, the classical theology highlighted their "greater propensity for sin" (Rosemary RUETHER, 1993, p. 84) based on the origin myth of Adam and Eve that "naturalized" women's guilt. In this way, blaming has always been a way of keeping women submissive and not rebelling against their submissive role at home and the Church. This text aims to focus on the struggle for protagonism of women from the periphery who started as members of Ecclesiastical Base Communities in the east of São Paulo and ended up creating a popular association - AMZOL - to lead social and political struggles in the region since the decade of 1960 . They became popular legal promoters, created the Maria Miguel Center (a sector of AMZOL) to fight domestic violence in partnership with the São Paulo State Attorney General's Office and ended up conquering important public policies. In order to highlight their trajectory as women from the periphery, this text begins with a brief historical review of how the industrial revolution and the advent of capitalism contributed to intensify the process of subordination and submission of women when they tried to enter the world of work, and then how the Vatican embarked on a crusade to combat the threat of militant atheism and communism through the Catholic Action, a project driven for the laity, in a yet patriarchal and quite elitist format. So, it was the feminist militancy that 
empowered the women from periphery and allowed important social and political achievements in the peripheries of large urban centers. Keywords: women in periphery, Church, protagonism, public policies, popular legal promoters.

\section{AMZOL: MUJERES DE LA PERIFERIA DE SÃO PAULO EN BUSCA DEL PROTAGONISMO}

\section{RESUMEN}

El protagonismo ha sido el gran objetivo a alcanzar por las mujeres en la Iglesia Católica, ante la negación de los ministerios ordenados y puestos de decisión por parte de su jerarquía. El cristianismo patriarcal que dominó a la Iglesia cristiana en la ortodoxia clásica presenta una religión dirigida a los hombres, ya que mostraba, en la perspectiva popular, a la mujer como portadora del pecado. Aunque permitió que una mujer reciba el Bautismo, la teología clásica enfatizó su "mayor propensión al pecado" (Rosemary RUETHER, 1993, p. 84), basado en el mito de origen de Adán y Eva que "naturalizó" la culpa de las mujeres. De esta manera, la culpabilización ha sido siempre una forma de mantener a las mujeres sumisas y no rebelarse contra su papel sumiso en el hogar y en la Iglesia. Este texto pretende centrarse en la lucha por el protagonismo de las mujeres de la periferia, que comenzaron como miembros de las Comunidades Eclesiásticas de Base en el este de São Paulo y terminaron creando una asociación popular - AMZOL - para liderar las luchas sociales y políticas en la región desde la década de 1960. Ellas se convirtieron en promotores legales populares, crearon el Centro María Miguel (un sector de AMZOL) para combatir la violencia doméstica en alianza con la Fiscalía General del Estado de São Paulo, y terminaron conquistando importantes políticas públicas. Para iluminar mejor su trayectoria como mujeres de la periferia, este texto comienza con una breve revisión histórica de cómo la revolución industrial y el advento del capitalismo contribuyeron a la intensificación del proceso de subordinación y sumisión de las mujeres cuando ellas intentaron ingresar al mundo del trabajo y luego cómo el Vaticano se embarcó en una cruzada para combatir la amenaza del ateísmo militante y el comunismo a través de la Acción Católica, un proyecto impulsado para los laicos, todavía patriarcal y bastante elitista. Así, fue la militancia feminista la que empoderó a las mujeres de las periferias y permitió importantes logros sociales y políticos en las periferias de los grandes centros urbanos.

Palabras clave: mujeres de la periferia, Iglesia, protagonismo, políticas públicas, promotoras legales populares. 


\section{AS MULHERES, A IGREJA, O CAPITALISMO E A CULPA}

O cristianismo patriarcal que dominou a Igreja cristã na ortodoxia clássica apresenta uma religião dirigida aos homens pois mostrou, na perspectiva popular, as mulheres como portadoras do pecado. Embora permitisse que as mulheres recebessem o Batismo, a teologia clássica ressaltava sua "maior propensão para o pecado" (Rosemary RUETHER, 1993, p. 84), baseada no mito de origem de Adão e Eva que "naturalizou" a culpa das mulheres. Desta forma, a culpabilização foi sempre uma forma de manter as mulheres submissas e garantir que não se rebelassem contra o seu papel de submissão no lar e na Igreja. Somente nós, mulheres, sabemos que sentimos culpa desde que nascemos. A teóloga Ivone Gebara afirma que as mulheres das bases têm mais dificuldade em captar a legitimação religiosa do sistema social hierárquico, pois o domínio do homem na ordem doméstica e pública foi sempre definido como comportamento para toda a humanidade (Ivone GEBARA, 1997). Caminhando para a época da revolução industrial, presenciamos os fatos que se desenrolaram no advento do capitalismo e como se deu o recrudescimento do processo de subalternidade e submissão a que as mulheres foram submetidas quando elas tentaram entrar para o mundo do trabalho.

O movimento de Reforma da Igreja, no século XVI, produziu o processo conhecido como "puritanismo", o qual se adaptou perfeitamente ao modo de produção capitalista nascente. Além disso, ele coincidiu com os ensinamentos do judeu-cristianismo no que se refere à sexualidade, que a concebia como uma energia maligna que devia ser reprimida com todo empenho. $O$ capitalismo encontrou no puritanismo um parceiro ideal para impor um modelo cultural que favorecesse a extração da mais-valia, domesticando o corpo e a sexualidade e, assim, reprimindo todo tipo de relações humanas. Neste sentido, o puritanismo foi o mecanismo utilizado pelas Igrejas para tornar a sexualidade o núcleo de seus ensinamentos pastorais. O pecado passou a ser identificado, principalmente, com as ações de cunho sexual, e os indivíduos deveriam focar seu comportamento na luta contra o pecado. O capitalismo sexista foi mais cruel com as mulheres: impôs às mulheres uma conduta direcionada aos cuidados intrafamiliares, tentando marginalizar as 
mulheres totalmente da vida pública. Foram marginalizadas de duas maneiras: como menores de idade, quase imbecis, ou colocando-as sob tutela. A elas foram atribuídas duas vocações: a da maternidade e a da virgindade consagrada, que se tornaram o símbolo do ideal tradicional da mulher. A exaltação dessas virtudes "próprias das mulheres" foi de muita serventia para os homens para as manterem em situação de submissão e elevarem a si mesmos à condução dos negócios mundanos e à direção da Igreja (Maria BIDEGAIN DE URÁN, 1984).

A reafirmação dos valores da família tradicional, insistindo no papel das mulheres dentro do lar, tinha um enfoque moralista que recaía sobre todos os relacionamentos, principalmente os amorosos, o namoro, a dança etc., insistindo na visão tradicional da sexualidade como o pecado capital e as mulheres como as incitadoras do mal, tornando-as detentoras do "pecado", enfim, as eternas culpadas.

\section{A AÇÃO CATOLICA}

Foi após a Primeira Guerra Mundial que as organizações em defesa dos direitos das mulheres e de sua maior participação na vida social, sindical e política, após sua efetiva entrada no mundo do trabalho, viram surgir a União Internacional da Ligas Católicas Femininas (1918) e o Movimento da Juventude Feminina (1922).

A Ação Católica, desde os finais do século XIX, foi apresentada como uma resposta à convocação que o Papado, preocupado com os rumos da sociedade que a cada dia se afastava da Igreja, dirigiu aos católicos para que se organizassem para realizar obras assistenciais, as quais deveriam ser dirigidas por sacerdotes, com o apoio das classes dirigentes locais. Este foi um movimento progressivo promovido por organizações permanentes de católicos militantes, que terminaram como uma verdadeira organização de massa. Não apenas se organizou o episcopado, mas também foram chamados os sacerdotes para organizar a Ação Católica nas suas paróquias. Na América Latina, o clero, em sua maioria, se entusiasmou com a possibilidade de participar de um apostolado laico, com uma ação pastoral assistencialista em favor das classes marginalizadas. O comunismo nascente se apresentava como um perigo e a difusão da doutrina social da Igreja tornava-se premente numa 
sociedade que se afastava a cada dia da doutrina cristã. A importância dada às mulheres na Ação Católica tinha a ver com a preservação da ordem tradicional da família cristã, contra a ameaça dos novos hábitos e costumes do mundo moderno (Maria BIDEGAIN DE URÁN, 1984).

A Ação Católica pareceu ser, dentro do catolicismo, uma doutrina positiva e eficaz, a única forma capaz de se opor ao ateísmo militante, ao comunismo e ao liberalismo, considerado então um relaxamento dos costumes. Deve-se acrescentar que os cursos para as mulheres eram dados em francês, excluindo assim, o contingente das classes menos abastadas. Isto significava que apenas as mulheres das elites estavam em condição de assumir a direção dessas associações nacionais.

As ligas femininas tiveram grande repercussão na vida cultural latino-americana, onde se enfatizava a "moralização" e os "bons costumes", principalmente nos setores médios. Às mulheres foram outorgadas responsabilidades, principalmente à medida que esquecessem sua "identidade feminina" e se lançassem ao trabalho "como homens".

\section{AS CEBS E AS MULHERES}

Como acabamos de ver, as Ligas das Senhoras Católicas contemplavam apenas as mulheres das elites ou, quando muito, das classes médias. Elas tinham a incumbência de exercer uma liderança em relação às outras mulheres no que consistia em ações assistencialistas como ajudar as famílias necessitadas, carentes, dando roupas, comida, encaminhando doentes para postos de saúde, crianças abandonadas para creches, etc. Nesse sentido, as mulheres de periferia eram apenas objeto de caridade, sem rosto, sem identidade.

Entretanto, o aparecimento das comunidades eclesiais de base (CEBs) nos anos de 1960 começou a mudar esse cenário, tanto para mulheres como para homens nas periferias dos centros urbanos. Vale lembrar que as cidades do sul do Brasil, em especial as do sudeste, começaram a ter um grande desenvolvimento a partir dos anos de 1950. O pós-guerra fez com que os países começassem a se preocupar com os meios de comunicação e transporte iniciando uma efetiva construção de rodovias e ferrovias, enquanto viam as cidades crescerem. As capitais do sudeste empreenderam a construção de grandes prédios, os chamados 
arranha-céus, e para isso tiveram de importar mão de obra barata que veio principalmente do nordeste, onde a seca empurrava os homens para o sul, em busca de emprego. No início, eles vieram sozinhos, mas, com o tempo, começaram a mandar buscar suas famílias. Foi assim que as periferias dos centros urbanos começaram a inchar, devido ao grande contingente de famílias em busca de moradia.

Incentivado pelos novos ares emanados pelo Concílio Vaticano II e a Conferência Episcopal de Medellin em 1968, e inspirado pela Teologia da Libertação, o clero progressista criou as comunidades eclesiais de base. O objetivo era a conscientização religiosa e política, assim como a mobilização dos pobres das zonas urbanas. Com o passar dos anos, as CEBs deram origem a um grande número de movimentos sociais. Os membros das CEBs eram incentivados a lutar pela mudança das estruturas religiosas, políticas e sociais. A participação em partidos políticos da esquerda era incentivada, em especial no Partido dos Trabalhadores (PT). Essas organizações de esquerda procuravam dar orientação política aos movimentos populares, deslocando alguns militantes dos centros para as periferias. Porém, uma das dificuldades, na época, era traçar planos conjuntos de ação. O país vivia sob a ditadura militar, o que significava a ausência de liberdades políticas, de expressão e de manifestação. Nesse aspecto, a ação do clero progressista foi decisiva. Este era jovem, a maioria na faixa etária entre 25 e 45 anos, tendo sido formado pelos ensinamentos da Teologia da Libertação latino americana, que estava em plena ebulição no Brasil nos anos 70. Vamos dar um exemplo: na zona leste, o bispo da região, D. Angélico Sândalo, identificava-se como teólogo da libertação, defendendo uma "opção preferencial pelos pobres". D. Angélico afirmava apoiar a criação de comunidades por dois motivos principais: porque elas eram um novo modo de ser igreja e também porque elas permitiam o desenvolvimento de uma conscientização política, tendo em vista a situação de penúria da população das periferias. Através da imprensa, em especial através do jornal diocesano Grita Povo, manifestava sua crença de que os problemas do Brasil se encontravam na dominação capitalista e na desigualdade de classes, que criava a pobreza e a exclusão social (Carol DROGUS, 1997). 
Desde o início, foram as mulheres que acorreram em grande número para a formação das comunidades, pois elas já participavam das atividades religiosas normais: missa, catequese, assistência aos mais pobres e doentes, etc. Amplamente falando, estimava-se que 66 a 90\% dos/as participantes eram do sexo feminino, sendo essa porcentagem referida à participação geral. Uma pesquisa informal em grupos de rua na Paróquia Santo Antônio estimou que 90\% dos/as participantes eram mulheres (Carol DROGUS, 1990).

Também os movimentos sociais na luta pela terra, pela moradia, pela saúde e contra a carestia contaram majoritariamente com a presença das mulheres. Por esse motivo, a Igreja se propôs a apoiar a criação dos Clubes de Mães que, no início, tinham o objetivo de reunir as mulheres para aprenderem costura ou algum trabalho manual que Ihes permitisse assegurarem uma renda própria. Assim, o Clube de Mães se tornou uma importante estratégia pastoral dirigida às mulheres, exatamente pelo elevado contingente delas nas CEBs.

As mulheres, em sua maioria, mostravam um profundo compromisso com a Igreja, onde participavam regularmente, a começar pela missa dominical. Algumas tinham uma participação mais efetiva, indo desde a limpeza da igreja até a participação como catequista. Diversas eram membras de grupos devocionais, como o Apostolado do Sagrado Coração, ou participavam de ministérios de assistência aos/às doentes ou similares. Assim, se acordo com a socióloga norte-americana Carol Drogus, a vida destas mulheres tinha duas dimensões distintas: a do cuidado dos filhos e da família, dentro da divisão sexual do trabalho e a dimensão do compromisso religioso pessoal, revelado dentro da ação assistencial e caritativa no âmbito da Igreja. Estas duas dimensões se entrelaçavam, criando uma base política de mobilização dentro dos espaços idealizados pela Teologia da Libertação. Essa mobilização se caracterizava por uma experiência de abertura aos/às outros/as, à comunidade, enfim, oo serviço para os/as outros/as (Carol DROGUS, 1997).

São Miguel Paulista é um dos bairros característicos da periferia de São Paulo, onde se encontram vilas operárias, favelas, prédios construídos em regime de mutirão, terrenos ocupados ilegalmente, etc. Nos anos 80 , cerca de $40 \%$ da população vivia em condições habitacionais 
consideradas inseguras, onde enchentes assolavam algumas áreas, como a da Paróquia Santo Antônio, arrastando as precárias habitações. Muitos moradores, e em especial as moradoras, são semialfabetizados/ as e têm uma das mais baixas rendas per capita do município. Como muitos habitantes da periferia urbana da América Latina, eles/as eram carentes de serviços básicos, desde escolas até a coleta de lixo. A tipificação dos/as membros/as da Paróquia Santo Antônio mostra que a maioria é constituída de mulheres, sobretudo empregadas domésticas, costureiras, donas de casa, trabalhadores e trabalhadoras de indústrias químicas e metalúrgicas, pequenos/as lojistas de bairro, vendedores/ as ambulantes. A região episcopal de São Miguel Paulista distinguiu-se nos anos 80 pela intensa atividade de suas comunidades eclesiais de base. Em suas 47 paróquias, havia cerca de 159 comunidades, das quais 30, aproximadamente, se situavam na paróquia Santo Antônio (cf. Que História é essa?, 1985)'.

\section{AMZOL E A PESQUISA DA REDE MULHER}

Na militância feminista dos anos de 1970, um grupo de mulheres de periferia da zona leste da cidade de São Paulo se destacou entre outros. Eram as mulheres da $\mathrm{AMZOL}^{2}$, já conhecidas desde os anos de 1980 por seu importante desempenho social e político.

A pré-história da AMZOL começa com mulheres cristãs de Clubes de Mães da região de São Miguel Paulista, num dia quente de novembro de 1984, com o início de uma pesquisa da Rede Mulher nessa mesma região. A Rede Mulher - uma ONG feminista de São Paulo - havia decidido fazer um Caderno como subsídio para o trabalho das mulheres dos Clubes de Mães e outros grupos de mulheres da zona leste de São Paulo. Essa pesquisa foi planejada para levantar dados históricos e detectar problemas e desafios sobre esses grupos/clubes de mães com o objetivo de contribuir com sua organização e atuação.

Esta é uma Cartilha da Rede Mulher, de 1985.

O primeiro contato que tive com as mulheres da AMZOL foi através das reuniões de Encontros Feministas que se organizaram em torno da Marcha Mundial de Mundial de Mulheres em 1992. Em 1998, fui convidada para dar algumas palestras sobre Bíblia e aí começou uma parceria que acabou me tornando uma militante de sua causa. 
Grande parte das mulheres que fundaram a $\mathrm{AMZOL}^{3}$ pertencia a comunidades da Paróquia Santo Antônio e arredores. Nesta Paróquia, as mulheres foram as responsáveis pela criação das comunidades de base. Uma mulher assim descreveu o início de sua comunidade: "Depois que nós, mulheres, conseguimos a terra e o material para o centro comunitário, nossos maridos nos ajudaram a construí-lo". As mulheres das comunidades de Santo Antônio não tinham dúvida sobre seu papel decisivo na formação e manutenção das CEBs: "Sem nós, sem o Clube de Mães”, informou Adelaide, da Vila Angélica, “não haveria Comunidade. Se amanhã fecharmos nossas portas, poderia ser o fim". Esta convicção foi confirmada por mulheres nas diversas comunidades visitadas ${ }^{4}$.

Na Paróquia Santo Antônio, um Clube de Mães tinha uma média de 15 a 20 mulheres e se constituía no núcleo de uma comunidade de base. A liderança do Clube normalmente coincidia com a liderança do ConseIho da comunidade. Cada uma de suas equipes era dedicada a tarefas especiais. As mulheres do Clube organizavam grupos de liturgia, cursos de batismo, catequese, aulas de alfabetização, reuniões políticas e os próprios movimentos sociais da comunidade (Que História é essa?, 1985).

Os clubes eram formados por mulheres, geralmente mães de filhos/ as pequenos/as, embora houvesse um pequeno número de mulheres solteiras na casa dos vinte anos. Geralmente não trabalhavam fora de casa, embora pudessem exercer atividades remuneradas em casa, como costura ou pequenos trabalhos manuais. Seu grau de instrução era baixo, muitas semi-analfabetas, algumas analfabetas. Várias delas começaram a frequentar os cursos de alfabetização depois que começaram a participar das CEBs.

Em 1994, a Rede Mulher fez uma pesquisa sobre os Clubes de Mães na região de São Miguel Paulista e verificou que lá havia 94 clubes de mães e grupos de mulheres, onde participavam cerca de 2.000 mulheres. Esses Clubes eram grupos de mulheres - mães ou não - ligados às

3 Grande parte dos textos sobre a AMZOL neste artigo fazem parte da minha tese de doutorado em Teologia Sistemática, defendida na Universidade Metodista de São Paulo no ano de 2004, sob o título: "Corpo e Cotidiano: A Experiência de Mulheres de Movimentos Populares desafia a Teologia Feminista da Libertação na América Latina”.

4 Entrevistas ref. por Carol Drogus (1997). 
comunidades de base que se reuniam para trabalhar, desenvolvendo diversas atividades: discussão dos problemas do bairro (41), trabalhos manuais (46), oração e reflexão (34), trabalho com famílias necessitadas (9), organização e avaliação dos trabalhos do bairro (8), distribuição de leite e alimentos (8), organização de feiras, chás e bazares (7) ginástica, teatro, recreação (6), troca de experiências pessoais (5), discussão sobre educação (4), reflexão sobre saúde (4), sobre planejamento familiar (1), etc. Na estatística apresentada, dos 94 clubes, 53 eram coordenados por mulheres, 19 eram coordenados por agentes externos, ou por mulheres com a ajuda de agentes externos. A média de participantes era de 10 a 20 participantes regulares. A maioria (70\%) se reunia uma vez por semana e 13 a cada 15 dias. Entretanto, esta pesquisa teve um limite: foi feita através do preenchimento de fichas. Isto significa que alguns grupos não foram levantados, por falta de organização ou por falta de uma articulação entre eles. Por outro lado, alguns grupos de mulheres não eram exatamente Clubes de Mães, isto é, funcionavam assim, mas não ajudavam as mulheres no sentido de uma conscientização. A grande maioria desses clubes e grupos foram organizados pelas ou através das comunidades de base (Igreja Católica Romana) (63), outros através da LBA (Legião Brasileira de Assistência) - normalmente dirigida pela primeira dama do país - (13), do movimento de saúde (5), de partidos políticos (2), do Centro Social (4), OSEM, SABs e Igreja Metodista (1 cada), etc. O grupo mais antigo havia sido fundado em 1956, 39 haviam sido fundados nos anos 70 e 54 entre os anos de 1980 a 1984. $\mathrm{Na}$ época da pesquisa, somente um dos 94 clubes e grupos cadastrados informou que tinha trabalhos sobre educação e direitos das mulheres (Que História é essa?, 1985).

A pesquisa da Rede Mulher mostra que quatro instituições são citadas como responsáveis principais desta organização feminina nos Clubes de Mães e nos grupos de mulheres em São Paulo: a Igreja Católica, a LBA (Legião Brasileira de Assistência), o Movimento de Saúde e a Prefeitura local. Um pequeno número teria se originado nas Sociedades Amigos do Bairro ( $S A B$ ), em entidades filantrópicas ou nos partidos políticos. A maneira como surgiram coloca como problemas evidentes a dependência institucional e a falta de um projeto próprio. A ficha cadastral preenchida 
durante a pesquisa da Rede Mulher na zona leste de São Paulo trouxe dados interessantes sobre este fato. A maioria dos Clubes e grupos não tinham denominação própria, apesar de existirem há mais de cinco ou dez anos. Eram geralmente referidos ao nome da comunidade ou do bairro em que se situavam. Muitas não tinham endereço próprio, fornecendo o endereço das paróquias, de alguma religiosa ou componente do Clube. A forma de coordenação dos clubes também é reveladora da dependência institucional e da falta de projeto próprio. Dos 94 clubes e grupos cadastrados, 38,54\% tinham coordenação própria na época. Os demais eram coordenados por agentes externos/as - padre, freira, assistente social - ou por mulheres do Clube em conjunto com agentes externos/as. Os que tinham coordenação própria, a exerciam somente em nível das iniciativas locais, já que sua atuação dependia do planejamento de outras instituições que estimulavam a participação das mulheres. Nenhuma dessas instituições incluiu, em sua plataforma, a discussão política da subordinação das mulheres como um problema social a ser resolvido (Moema VIZZER, 1989).

Os Clubes de Mães nasceram com objetivos diferentes. A maioria se dedicava aos trabalhos manuais. Ao mesmo tempo em que refletiam sobre o Evangelho, outros grupos se voltavam para assistir às pessoas idosas e/ou doentes. E, finalmente, de modo geral, estavam despertando para as lutas nos bairros: movimento do custo de vida, contra o lixão, pela criação de creches, postos de saúde, por água, pela moradia. Com o decorrer do tempo, em sua grande maioria, os clubes foram se modificando e ampliando seus objetivos. Também tiveram origens diferentes: os da zona leste, foram criados a partir de 1975 e pela iniciativa de padres, freiras e agentes de pastoral encarregados de dinamizar as CEBs. Os da zona sul foram criados a partir da iniciativa das próprias mulheres, incentivadas por agentes de organizações feministas. Embora alguns já existissem nos anos 60 , foi a partir do final dos anos 70 que 0 número de Clubes de Mães tornou-se significativo. Ao que tudo indica, o impacto criado pelas discussões e ações empreendidas a partir da Década da Mulher (1975-1985), promovida pelas Nações Unidas, repercutiu na multiplicação desses clubes. Também foi revelado na pesquisa da Rede Mulher que os Clubes de Mães influíram muito na configuração 
das CEBs. Na expressão de uma das entrevistadas, o Clube de Mães é como "a mãe de outros movimentos do bairro". Geralmente "é do Clube de Mães que saem outros grupos para formar a comunidade". Muitas vezes, "é o clube que inicia uma luta, depois a comunidade toda apóia" (Moema VIZZER, 198, p. 62-66).

De uma forma geral, as mulheres reconheciam o valor da ação do clero progressista, voltado para a organização do povo, mas também percebiam a outra face, aquela que não conseguia lidar com as questões específicas das mulheres, inclusive os conflitos sobre as relações de poder e decisão na Igreja:

"A questão também é ver o papel da mulher na Igreja, né? A Igreja católica perde nesse ponto, sabe? Porque a Metodista já tem pastora e na Católica ainda o padre é o "mandachuva”. Mas a briga que está sendo aí, vai ainda mais longe: é pra que o povo seja essa lgreja, em que as mulheres tenham participação!" (Que História é essa?, 1985).

Indo mais além, elas descobriram que seus "assuntos de mulher" não encontravam espaço para serem discutidos, dentro do espaço da Igreja.

"A gente percebe que a Igreja ajudou a conscientizar a mulher, a ter maior liberdade, a deixar de ser escrava. Mas agora a gente está percebendo que está sendo escrava, porque foi assumindo mil coisas no movimento popular, na liturgia, na catequese e não sei o quê mais. $\mathrm{E}$ falta espaço e tempo pra discutir nossos assuntos, de mulher. E isso faz falta mesmo, sabe?" (Que História é essa?, 1985).

A discussão de assuntos específicos como o corpo, a sexualidade, o prazer, os métodos contraceptivos, a violência doméstica, o aborto, o estupro, etc., eram malvistos. Eram criticados não só pelos dirigentes da Igreja, mas também pelos políticos de esquerda, que alegavam que assuntos específicos "só dividem o movimento operário, enfraquecendo a luta conjunta pelas transformações sociais". As mulheres perceberam que só lhes era permitido falar sobre a educação dos/as filhos/as, o cuidado da família, a discriminação no trabalho, os problemas da comunidade, enfim, assuntos gerais. As agentes feministas eram abordadas 
e cercadas nos bairros, e impedidas de falar nas comunidades (Maria TELES, 1993).

Até que, finalmente, algumas mulheres das comunidades decidiram sair em busca de espaço fora da Igreja: "O nosso grupo é independente. E eu vejo assim: com igreja ou sem igreja, com religião ou sem ela, o importante é a gente ter claro na cabeça por quê as mulheres se reúnem" (Que História é essa?, 1985).

A conscientização política também atingiu um nível respeitável, pois as mulheres passaram a falar com segurança sobre a política partidária e como encaminhar seus interesses dentro do emaranhado político que agitava os bairros de periferia:

“É importante que a gente entenda de política porque a política envolve todo o mundo. O que não pode é impor política partidária dentro do clube." "Precisamos ter a nossa formação política, pra gente ver como vamos encaminhar as lutas dentro de nossa realidade de mulheres exploradas" (Que História é essa?, 1985).

Foi nessa atmosfera de conscientização feminista propiciada pela pesquisa da Rede Mulher que um grupo de mulheres se reuniu para discutir seus problemas frente aos conflitos que começaram a surgir dentro dos Clubes de Mães, que funcionavam em espaços cedidos pela Igreja. Segundo elas, nas CEBs, e mesmo nos Clubes de Mães, não havia espaço para falar de seus "assuntos de mulher". Além disso, cada vez ficava mais claro que sua liderança não era respeitada, justamente por serem mulheres. E foi assim que surgiu a AMZOL (Associação de Mulheres da Zona Leste), totalmente independente da Igreja e com autonomia para desempenhar um protagonismo de mulheres conscientes de seus direitos e na busca de políticas públicas.

Em uma entrevista que nos deu Cida Lima, (em 2001), ela nos contou:

"Éramos mulheres dos clubes de mães: lutando por rua asfaltada, por luz, por creche, pela saúde. Nós chamávamos as mulheres toda vez que precisava juntar um grupo de pessoas pra tá indo pressionar o prefeito, o governador, sempre eram essas mulheres que iam. Quando chegava na hora de pegar um microfone e falar, era sempre um homem que 
falava, principalmente os políticos, então nós começamos a perceber o quanto que nós éramos usadas nos movimentos, a gente fazia os movimentos, fazia isso, aquilo e as mulheres nunca apareciam. Quem sempre aparecia era um homem, um vereador, um deputado, então isso nos deu uma consciência que a mulher tinha que assumir seu papel na sociedade, foi quando a gente em 1985 decidiu fundar uma associação aqui no Itaim Paulista, na zona Leste. E assim foi fundada a AMZOL, Associação de Mulheres da Zona Leste, em 1987 (Cida LIMA5, entrevista realizada em 2001) ${ }^{6}$.

\section{O CENTRO MARIA MIGUEL E A LUTA CONTRA A VIOLÊNCIA DOMÉSTICA}

No início da década de 90, as lideranças da AMZOL, conscientes da terrível situação de violência sexual e doméstica das mulheres nos centros urbanos, participaram do Curso de Promotoras Legais Populares, promovido pela União de Mulheres de São Paulo7. Vendo seu entusiasmo, em 1996, a Procuradoria Geral do Estado ofereceu uma parceria para a AMZOL com vistas à criação de um convênio para o atendimento de mulheres que sofrem violência doméstica. Em setembro desse mesmo ano, foi celebrado um convênio com a duração de cinco anos entre a AMZOL e a Procuradoria, que depois foi renovado por mais cinco anos. Uma verba era disponibilizada para o pagamento mensal de três advogadas e três estagiárias. Desta forma, foi criado o Centro Maria Miguel ${ }^{8}$ de Atendimento à Mulher em Situação de Violência, como um Departamento da AMZOL. Através do Centro Maria Miguel, as

5 Cida Lima é uma das fundadoras da AMZOL. Ela é negra, solteira, militante do PT, nascida na zona leste, filha de humildes migrantes mineiros. Na época, era a presidente da AMZOL.

6 Além de Cida Lima, quero lembrar aqui o nome de D. Ilza, que foi a presidente da Associação desde seu início até o ano de 1999, quando se mudou para Minas Gerais para acompanhar o marido. Foi a maior liderança dessa entidade. Gostaria de lembrar o nome de outras mulheres que foram também grandes guerreiras, mas no momento não as tenho de memória. Mulheres simples como D. Maria Miguel também tem que ser lembradas, por sua garra, sua constância, sua bondade e solidariedade.

7 Nos anos de 1990 ficamos conhecendo a União Popular de Mulheres de São Paulo, presidida por Maria Amélia de Almeida Teles, uma das mais importantes líderes feministas brasileiras. O principal trabalho dessa organização feminista, nessa época, foi o curso de PROMOTORAS LEGAIS POPULARES.

8 D. Maria Miguel foi uma integrante muito respeitada por sua garra e luta pela causa das mulheres populares que, a essa época, tinha se retirado pela avançada idade e dificuldade de locomoção. 
promotoras populares tinham a tarefa de atender com eficiência todas as mulheres que procuravam a entidade para obter apoio, informação, assistência jurídica, etc. Esse atendimento visava não somente atender juridicamente às mulheres em situação de violência, mas também dar a elas apoio emocional e espiritual, assim como atendimento psicológico e assistencial à família.

Em 2001 a AMZOL concorreu, juntamente com mais de vinte entidades sociais, ao Prêmio Betinho 2001 - Democracia e Cidadania, promovido pela Câmara dos Vereadores de São Paulo. No mês de outubro de 2001, a AMZOL conquistou, juntamente com outras duas entidades, o prêmio referido, pelo trabalho sobre violência doméstica do Centro Maria Miguel.

\section{À GUISA DE CONCLUSÃO}

Vários são os méritos, as conquistas, as dificuldades e os desafios enfrentados pelas organizações populares de mulheres. Entre todas as atividades elencadas, o maior mérito da AMZOL, a meu ver, foi a sua atuação política na região. Em época de eleições, todas as mulheres iam para as ruas afim de promoverem os/as candidatos/as da região e fazer boca de urna. Quase a totalidade dos/as candidatos e candidatas apoiadas/os eram do Partido dos Trabalhadores (PT). Embora a maioria não tivesse emprego nem salário, saíam às ruas para fazer propaganda de seus/suas candidatos/as, porque acreditavam que só assim poderiam mudar a situação de seu bairro, de sua cidade, de sua família e poderiam lutar por políticas públicas. Foram elas as lideranças responsáveis por grande parte das políticas públicas sobre saúde, educação, segurança e moradias nas periferias nesse período. Só depois de ver a mobilização e a atuação dessas mulheres na região, pode-se compreender a força do movimento feminista na atuação política em nosso país. Mulheres fortes, mulheres guerreiras!

Também quero destacar o papel do Curso de Promotoras Legais Populares oferecido pela União Brasileira de Mulheres, em São Paulo?.

Para mas informações, ver: < https://pt.calameo.com/read/004583414f8bc242ff63f > e < uniaodemulheres.com.br >. 
Para finalizar, quero enfatizar que os pontos que mais me impressionam, ainda hoje, são a força, a resistência e a resiliência dessas mulheres por terem tido a coragem de romper com a Paróquia que não mais as acolhia e por terem decidido se reunir em outro lugar para discutir os assuntos de sexualidade, que eram parte fundamental de sua vida cotidiana familiar e algo que as afligia e sufocava. Esse rompimento traz um simbolismo: de que as mulheres das bases são capazes de compreender os nós patriarcais das relações sociais e religiosas às quais são submetidas dentro e fora da Igreja, apesar de todas as dificuldades mencionadas com precisão por Ivone Gebara em seu livro. As mulheres continuaram a frequentar as celebrações religiosas, como de costume. Algumas até continuaram a participar de suas pastorais, agora com mais consciência de que também podiam ser protagonistas.

Embora essa minha militância com mulheres de periferias já tenha acontecido há bastante tempo, achei importante registrar a importância delas para o movimento feminista, para o protagonismo dentro e fora da Igreja, para a luta por políticas públicas e por aquilo em que acreditavam. E uma coisa que mencionei sem ter dado tanto destaque foi a questão do debate sobre a sexualidade na Igreja Católica. Eu, como teóloga feminista, tenho sentido esse problema na pele, porque já dei várias palestras sobre temas como sexualidade, reprodução, homossexualidade, virgindade de Maria ou direitos reprodutivos e, fora dos espaços acadêmicos, dentro de espaços do clero, sempre houve reações adversas. Mesmo entre os teólogos da libertação, são poucos os que tratam do tema da sexualidade e, quando o fazem, é sempre tangencialmente. Por isso insisto, aqui, que temos que lutar pelas causas que nos tocam de perto: as questões de gênero e sexualidade, de raça, de orientação sexual, de deficiência física ou mental, geracional, etc., sempre lembrando que "o teu problema é meu problema".

\section{BIBLIOGRAFIA}

ALVAREZ, Sonia E. Women's Participation in the Brazilian "People's Church": a Critical Appraisal. In: LEVINE, Daniel H. (Ed.). Religion and Political Conflict in Latin America. Chapel Hill and London: The Univ. North Carolina Press, 1986, pp. 381-408. 
BIDEGAIN DE URÁN, A. Maria. Sexualidade, Vida Religiosa e Situação da Mulher na América Latina. In: MARCÍLIO, M. Luiza (Org.). A Mulher Pobre na História da Igreja Latino-Americana. São Paulo: Paulinas, 1984.

DROGUS, Carol Ann. Reconstructing the Feminine: Women in São Paulo's CEBs. Archives de sciences sociales des religions, n. 71, 1990, pp. 63-74.

DROGUS, Carol. Women, Religion, and Social Change in Brazil's Popular Church. Notre Dame, Indiana: Univ. Notre Dame Press, 1997.

GEBARA, Ivone. Teologia Ecofeminista: Ensaio Para Repensar o Conhecimento e a Religião. São Paulo: Olho d’Água, 1997.

TELES, Maria Amélia de A. Breve História do Feminismo no Brasil. São Paulo: Editora Brasiliense, 1999.

VIZZER, Moema. O Problema não está na Mulher. São Paulo: Cortez, 1989.

VIZZER, Moema. Aos Animadores de Grupos de Rua: de 1979 até 1985, 1986.

VIZZER, Moema. Que História é essa? Clube de Mães e Grupos de Mulheres de São Paulo. Publ. GEP-URPLAN/REDE MULHER, 1985.

VIZZER, Moema (org.). "Retrato" dos Clubes de Mães e Grupos de Mulheres da Zona Leste de São Paulo. São Paulo: Edições Rede Mulher. 1985.

RUETHER, Rosemary Radford. Sexismo e Religião. Rumo a uma teologia feminista. São Leopoldo, RS: Sinodal, 1993.

Submetido em: 14-9-2021

Aceito em: 22-11-2021 